\title{
ONE-POT SYNTHESIS BENZILS FROM ALDEHYDES VIA NHC-CATALYZED BENZOIN DIMERIZATION UNDER METAL-FREE CONDITIONS IN WATER
}

\author{
XIAOXIN BI ${ }^{1}$, LINTAO WU ${ }^{1}$, CHAOGUO YAN ${ }^{1}$, XIAOBI JING ${ }^{11^{*}}$, HONGXIANG ZHU \\ ${ }^{I}$ College of Chemistry and Chemical Engineering, Yangzhou University, Yangzhou 225002, P. R. China \\ ${ }^{2}$ School of Light Industrial and Food Engineering, Guangxi University, Nanning, P. R. China
}

(Received: June 23, 2010 - Accepted: May 12, 2011)

\begin{abstract}
A simple and convenient one-pot procedure is reported for the synthesis of 1,2-diketones from corresponding benzoin-type condensation reaction of aromatic aldehydes in water with $N, N$-dialkylbenzimidazolium salt as condensation catalyst and air as oxidizing reagent.
\end{abstract}

Keywords: benzils; benzoin condensation; benzimidazolium salts; metal-free oxidation

\section{INTRODUCTION}

Benzils have received a great deal of attention because of their applications as photosensitive reagents in photocurable coatings, ${ }^{1}$ as starting materials in organic and pharmaceutical synthesis, ${ }^{2}$ and also as biologically active compounds. ${ }^{3}$ Conventionally benzils are prepared by coupling of acid chlorides with $\mathrm{SmI}_{2},{ }^{4}$ and oxidation of mono ketones with $\mathrm{SeO}_{2} .{ }^{5}$ Oxidation of acetylenes with $\mathrm{NaIO}_{4} / \mathrm{RuO}_{2}{ }^{6}, \mathrm{Tl}\left(\mathrm{NO}_{3}\right)_{3}{ }_{3}$, and $\mathrm{KMnO}_{4}{ }^{8}$ has been reported to afford $\alpha$-diketones in lower yields. Some complex and expensive reagents, such as 4-Me-TEMPO, ${ }^{\text {a a }}$ (4-AcNH-TEMPO)-OTs-TsOH, ${ }^{\text {gb }}$ 4-phCO ${ }_{2}$-TEMPO, ${ }^{\text {c }}$ $n-\mathrm{Bu}_{4} \mathrm{~N}\left[\mathrm{MoO}(\mathrm{O})_{2}\left(\mathrm{C}_{5} \mathrm{H}_{4} \mathrm{~N}(\mathrm{O}) \mathrm{O}_{2}\right)\right],{ }^{10} \quad \mathrm{H}_{2} \mathrm{O}_{2}-\left[\mathrm{C}_{5} \mathrm{H}_{5} \mathrm{~N}-\left(\mathrm{CH}_{2}\right)_{15} \mathrm{CH}_{3}\right]_{3}{ }_{3} \mathrm{PO}_{4}[\mathrm{~W}(\mathrm{O})$ $\left.\left(\mathrm{O}_{2}\right)\right]_{4}$, , 11 can oxidize 1,2-diols to 1,2-diketones. Benzils can also be prepared by the oxidation of corresponding benzoins with oxidizing agents such as $\mathrm{CuSO} / \mathrm{Py}, \mathrm{Bi}_{2} \mathrm{O}_{3} / \mathrm{H}^{+}, \mathrm{HNO}_{3}$ in aq. solution, ${ }^{12} \mathrm{RuO}_{4}{ }^{13}$. And all these methods have its drawbacks in terms of expensive regents, difficult reaction conditions and low yields. Recently, we reported our work on the synthesis of benzils using $\mathrm{FeCl}_{3}$ as oxidizing reagent ${ }^{14}$, Herein, we disclose our new result.

Results and Discussion

In the past decade, there has been a dramatic increase in the use of $\mathrm{N}$-heterocyclic carbenes (NHCs) in synthetic organic chemistry. NHCs are versatile ligands that can be used in homogenous transition metal catalysis. ${ }^{15}$ Furthermore, considerable attention has been paid to the use of NHCs as organocatalysts. ${ }^{16}$ In 2006, Iwamoto $^{17}$ reported that benzoin condensation reaction can be catalyzed by $N, N$-dialkylbenzimidazole in water to yield $\alpha$-hydroxy ketones. We repeated this reaction and found that if room temperature stirring was replaced by refluxing, the yield of benzoin was increased to $92 \%$ and the reaction time was only $0.5 \mathrm{~h}$. (Scheme 1)

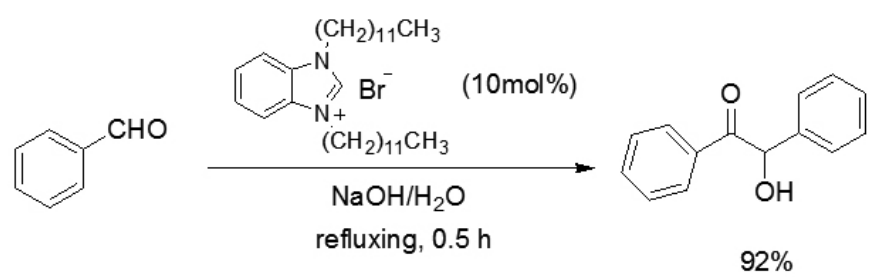

Scheme 1: Benzoin reaction catalyzed by benzimidazolium salts in water by refluxing.

But when we prolonged the reaction time to $1 \mathrm{~h}$, the yield of the $\alpha$-hydroxy ketone was decreased and the amount of byproduct which is benzil was increased. If the reaction was repeated in the atmosphere of nitrogen, a small amount $(<5 \%)$ of benzil was formed. So it can be concluded that in the reaction process some of $\alpha$-hydroxy ketones was oxidized to benzil by the oxygen in the air. So we prolonged the reaction time to $2 \mathrm{~h}$ and obtained benzil in good yield $(85 \%)$.

To optimize the reaction condition we examined this domino reaction with varying ben- zimidazolium salts, solvent and time by using the reaction of benzaldehyde as an comparing reference. (Scheme 2) The results are summarized in Table 1 and Table 2.

From the Table 1, it can be seen that the octyl substituted benzimidazole(2e) is the best catalyst in this reaction and from table 2 , it can be seen that water is the best solvent for this reaction.

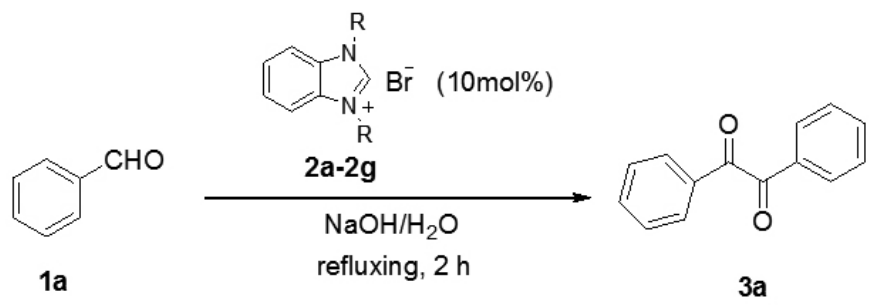

Scheme 2 Route to benzil from aldehyde through benzoin dimerization under metal-free conditions

Table 1: Synthesis of benzils catalyzed by varying benzimidazolium salt

\begin{tabular}{|c|c|c|c|c|}
\hline Entry & Catalyst & $\mathrm{R}$ & Time(h) & Yield \% \\
\hline 1 & $2 \mathrm{a}$ & $\mathrm{CH}_{2} \mathrm{CH}_{3}$ & 2 & 32 \\
\hline 2 & $2 \mathrm{~b}$ & $\mathrm{CH}_{2} \mathrm{CH}_{2} \mathrm{CH}_{3}$ & 2 & 55 \\
\hline 3 & $2 \mathrm{c}$ & $\mathrm{CH}_{2}\left(\mathrm{CH}_{2}\right)_{2} \mathrm{CH}_{3}$ & 2 & 63 \\
\hline 4 & $2 \mathrm{~d}$ & $\mathrm{CH}_{2}\left(\mathrm{CH}_{2}\right)_{3} \mathrm{CH}_{3}$ & 2 & 72 \\
\hline 5 & $2 \mathrm{e}$ & $\mathrm{CH}_{2}\left(\mathrm{CH}_{2}\right)_{6} \mathrm{CH}_{3}$ & 2 & 85 \\
\hline 6 & $2 \mathrm{f}$ & $\mathrm{CH}_{2}\left(\mathrm{CH}_{2}\right)_{10} \mathrm{CH}_{3}$ & 2 & 82 \\
\hline 7 & $2 \mathrm{~g}$ & $\mathrm{CH}_{2}\left(\mathrm{CH}_{2}\right)_{14} \mathrm{CH}_{3}$ & 2 & 80 \\
\hline
\end{tabular}

Table 2 Synthesis of benzils in different solvents.

\begin{tabular}{|c|c|c|c|}
\hline Entry & Solvent & Time(h) & Yield \% \\
\hline 1 & $\mathrm{CH}_{3} \mathrm{CH}_{2} \mathrm{OH}$ & 2 & 67 \\
\hline 2 & $\mathrm{CH}_{3} \mathrm{OH}$ & 2 & 36 \\
\hline 3 & $\mathrm{H}_{2} \mathrm{O}$ & 2 & 85 \\
\hline 4 & $\mathrm{THF}$ & 2 & 55 \\
\hline
\end{tabular}

Under optimized conditions ${ }^{18}$ (catalyzed of $2 \mathbf{e}$ in water), the reactivity of a series of aromatic aldehydes in this reaction was examined (Scheme 3), the results are summarized in Table 3. From the table it can be seen that aromatic aldehyde bearing chloro-, bromo- and methyl substituent afforded the desired benzils in higher yields within shorter reaction time. While the reactions of 3- or 4-nitrobenzaldehyde or $p$-hydroxyl benzaldehyde were considerably slow and the yields of corresponding benzils were very low. Furfural also gave the product of furil with good yield. 


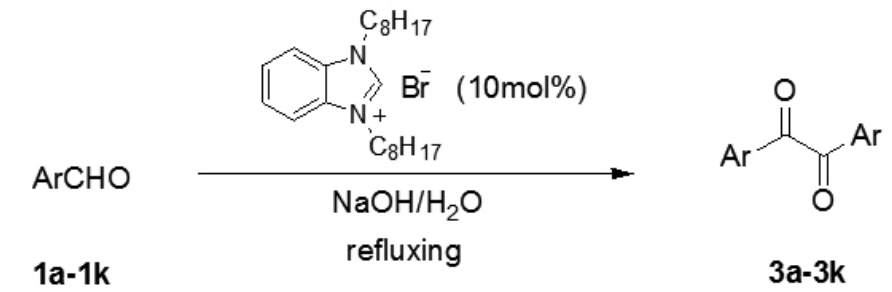

Scheme 3: One-pot synthesis of a-diketones from aldehydes.

Table 3: The synthesis of benzils in one-pot reaction.

\begin{tabular}{|c|c|c|c|c|c|}
\hline Entry & $\mathrm{Ar}$ & Product & Time $(\mathrm{h})$ & Yield $\%$ & $\mathrm{Mp}\left({ }^{\circ} \mathrm{C}\right)$ \\
\hline 1 & $\mathrm{Ph}$ & $3 \mathrm{a}$ & 2 & 85 & $95-96$ \\
\hline 2 & $4-\mathrm{Me}-\mathrm{C}_{6} \mathrm{H}_{4}$ & $3 \mathrm{~b}$ & 2 & 80 & $103-105$ \\
\hline 3 & $4-\mathrm{MeO}-\mathrm{C}_{6} \mathrm{H}_{4}$ & $3 \mathrm{c}$ & 2.5 & 75 & $130-131$ \\
\hline 4 & $4-\mathrm{OH}-\mathrm{C}_{6} \mathrm{H}_{4}$ & $3 \mathrm{~d}$ & 4 & none & --- \\
\hline 5 & $4-\mathrm{Cl}_{6} \mathrm{C}_{6} \mathrm{H}_{4}$ & $3 \mathrm{e}$ & 1.5 & 94 & $195-198$ \\
\hline 6 & $3-\mathrm{Br}_{6} \mathrm{C}_{6} \mathrm{H}_{4}$ & $3 \mathrm{f}$ & 1.5 & 86 & $122-124$ \\
\hline 7 & $4-\mathrm{Br}_{6} \mathrm{C}_{6} \mathrm{H}_{4}$ & $3 \mathrm{~g}$ & 1.5 & 80 & $224-226$ \\
\hline 8 & $4-\mathrm{NO}_{2}-\mathrm{C}_{6} \mathrm{H}_{4}$ & $3 \mathrm{~h}$ & 4 & trace & --- \\
\hline 9 & $3-\mathrm{Cl}_{-} \mathrm{C}_{6} \mathrm{H}_{4}$ & $3 \mathrm{i}$ & 1.5 & 90 & $114-116$ \\
\hline 10 & $3-\mathrm{NO}_{2}-\mathrm{C}_{6} \mathrm{H}_{4}$ & $3 \mathrm{j}$ & 4 & trace & --- \\
\hline 11 & Furan-2-yl & $3 \mathrm{k}$ & 1.5 & 85 & $165-166$ \\
\hline
\end{tabular}

\section{CONCLUSIONS}

In conclusion, as described above, we developed a one-pot synthesis of benzils by the domino reaction of aldehydes with benzimidazolium salt as catalyst and the oxygen in the air as oxidizing reagent. The present reaction with its mild and metal-free conditions opens a novel green entry to synthesis of benzils by simple procedure.

\section{ACKNOWLEDGMENTS}

This research was supported by the Cultivation and Construction Found for the State Key Subject of Physical Chemistry.

\section{REFERENCES AND NOTES}

1. (a) Matsushita Electric Industrial Co. Ltd., Jpn. Kokai Tokyo Koho, 1981; (b) Chem. Abstr. 1981, 95, 188163u.

2. J. Mattay, J. Runsink, J. Org. Chem. 50, 2815, (1985).

3. L. R. Hillis, R. C. Ronald, J. Org. Chem. 50, 470, (1985).

4. J. Souppe, J.-L Namy, H. B. Kagan, Tetrahedron Lett. 25, 2869, (1984).

5. N. Rabjohn, Org. React. 5, 331, (1949).

6. R. Zibuck, D. Seebach, Helv. Chim. Acta. 71, 237, (1988).

7. R. McKillop, O. H. Oldenziel, B. P. Swann, E. C. Taylor, R. L. Robey, J. Am. Chem. Soc. 95, 1296, (1973).

8. D. G. Lee, V. S. Chang, Synthesis, 462, (1978).

9. (a) P. L. Anelli, S. Banfi, F. Montanari, S. Quici, J. Org. Chem. 54, 2970, (1989). (b) M. G. Banwell, V. S. Bridges J. R.Dupuche, S. L. Richards, J. M. Walter, J. Org. Chem., 59, 6338. (1994). (c) J. Inokuchi, S. Matsumoto, T. Nishiyama, S. Torii, Synlett, 57, (1990).

10. S. Campestrini, F. D. Furia, G. Modena, J. Org. Chem. 55, 3658, (1990).

11. T. Iwahama, S. Sakaguchi, Y. Nishiyama, Y. Ishii, Tetrahedron Lett. 36, 1523, (1995).

12. (a) W. Rigby, J. Chem. Soc. 793, (1951). (b) H. T. Clarke, E. E. Dreger, Org. Synth. Coll. 1, 87, (1941).

13. S. Baskaran, J. Das, S. Chandrasekaran, J. Org. Chem. 54, 5182, (1989).

14. X. B. Jing, X. Pan, Z. Li, Y. C. Shi, Syn. Commn. 39, 492, (2009).

15. (a) S. Díez-González, N. Marion, S. P. Nolan, Chem. Rev. 109, 3612, (2009). (b) F. E. Hahn, M. C. Jahnke, Angew. Chem. Int. Ed. 47, 3122, (2008). (c) Topics in Organometallic Chemistry, Vol. 21; Glorius, F. Ed.; Springer: Berlin, 2007; (d) R. E. Douthwaite, Coord. Chem. Rev. 251, 702, (2007). (e) E. A. B. Kantchev, C. J. O'Brien, M. G. Organ, Angew. Chem. Int. Ed. 46, 2768, (2007). (f) W. A. Herrmann, Angew. Chem. Int. Ed. 41, 1290, (2002).

16. (a) D. Enders, O. Niemeier, A. Henseler, Chem. Rev., 107, 5606, (2007). (b) H. Clavier, S. P. Nolan, Annu. Rep. Prog. Chem., Scet. B. 103, 193, (2007).

17. K. Iwamoto; M. Hamaya. Tetrahedron Lett. 47, 7175, (2006). 